\title{
Tratamiento de secuelas tardías de cicatrices en quemaduras utilizando la fracción del estroma vascular derivada del tejido adiposo. Serie de casos y revisión de la literatura
}

\section{Treatment of late sequels of scars in burns using the stroma vascular fraction of adipose tissue. Case series and literature review}

\author{
José H. Sandoval-Pérez" ${ }^{*}$, Bruno Balmelli-Forno², Celso Aldana-Ubillus ${ }^{3}$ y Derliz Alban-Mussi4 \\ ${ }^{1}$ Unidad de Cirugía Plástica, Hospital de Clínicas y Centro Nacional de Quemaduras y Cirugía Reconstructiva (CENQUER); ${ }^{2}$ Dirección, Hospital \\ CENQUER-MSP; ${ }^{3}$ Unidad de Cirugía Plástica, Hospital de Clínicas; ${ }^{4}$ Cirugía Plástica, Sociedad Paraguaya de Cirugía Plástica, Reconstructiva y \\ Estética. Asunción, Paraguay
}

\begin{abstract}
Resumen
Introducción: El tejido adiposo obtenido mediante liposucción es una fuente idónea para aislar células con potencial terapéutico, las denominadas células de la fracción del estroma vascular, que se han convertido en una de las principales herramientas de terapia celular autóloga para diversas aplicaciones médicas. Objetivo: Demostrar los efectos funcionales y estéticos de la aplicación de la fracción del estroma vascular derivada de tejido adiposo autólogo para el tratamiento en secuelas tardías de quemaduras. Material y métodos: Estudio analítico, tipo serie de casos de pacientes con cicatrices por quemaduras. Se realizaron mediciones con escalas y microscopia óptica para la evaluación. Resultados: No hubo complicaciones locales o sistémicas relacionadas con el procedimiento, con mejoría respecto a las escalas de evaluación y a la microscopia óptica. Ventaja clínica, en la capacidad funcional y en la angiogénesis. Conclusión: La remodelación de las cicatrices utilizando fracción derivada de tejido adiposo puede plantearse como alternativa en el manejo conjunto o aislado de las cicatrices por quemaduras.
\end{abstract}

Palabras clave: Lipoaspiración. Cicatrices por quemaduras. Fracción derivada del estroma vascular.

\begin{abstract}
Background: The adipose tissue obtained by liposuction is an ideal source to isolate cells with therapeutic potential, the so-called cells of the vascular stromal fraction, which have become one of the main tools of autologous cell therapy for various medical applications. Objective: To demonstrate the functional and aesthetic effects of the application of the fraction of the vascular stroma derived from autologous adipose tissue for the treatment of late sequelae of burns. Material and methods: Analytical study, case series type of patients with burn scars. Measurements were made with scales and optical microscopy for evaluation. Results: There were no local or systemic complications related to the procedure, with improvement regarding the evaluation scales and light microscopy. Clinical advantage, in functional capacity and in angiogenesis. Conclusion: The
\end{abstract}

Correspondencia:

*José H. Sandoval-Pérez

E-mail: sandovalperez@ hotmail.com
Disponible en internet: 09-04-2021

Rev Hosp Jua Mex. 2021;88(1):8-16

www.revistahospitaljuarez.com licencia CC BY-NC-ND (http://creativecommons.org/licenses/by-nc-nd/4.0/). 
remodeling of scars using fraction derived from adipose tissue can be considered as an alternative in joint or isolated management of burn scars.

Key words: Liposuction. Scars. Burns. Derived stromal vascular fraction.

\section{Introducción}

Las fibrosis derivadas de cicatrices por quemaduras siguen siendo un reto en la medicina plástica reconstructiva, no solo por el aspecto estético, sino también por las contracturas finales que pueden afectar la función de algún miembro'.

Las mejoras en el cuidado de las quemaduras agudas han permitido a los pacientes sobrevivir a quemaduras masivas que antes habrían sido fatales. Ahora hasta el $70 \%$ de los pacientes desarrollan cicatrices hipertróficas después de quemaduras. Las secuelas funcionales y psicosociales siguen siendo un gran desafío de rehabilitación, disminuyendo la calidad de vida y retrasando la reintegración en la sociedad. Los enfoques para optimizar el potencial de curación de las heridas por quemaduras utilizan el cuidado y la cirugía de heridas específicas para minimizar el desarrollo de cicatrices hipertróficas. Tales enfoques a menudo fallan, y la modulación de la cicatriz establecida continúa, aunque la indicación óptima, el momento y la combinación de terapias aún no se han implantado. La necesidad de nuevos tratamientos es primordial, y los esfuerzos futuros para mejorar los resultados y la calidad de vida deben incluir la optimización de la cicatrización de heridas para atenuar o prevenir la cicatrización hipertrófica, ensayos bien diseñados para confirmar la eficacia del tratamiento y una mayor aclaración de los mecanismos moleculares para permitir el desarrollo de nuevas estrategias preventivas y terapéuticas ${ }^{1}$.

La importancia de las vías de señalización beta del factor de crecimiento transformante y las moléculas efectoras relacionadas han demostrado ofrecer una nueva visión detallada de la biología de las cicatrices. La regulación del metabolismo de la cicatriz con respecto a la degradación del colágeno y la matriz de la herida también es prometedora en la generación de terapias alternativas para tratar cicatrices anormales².

Las intervenciones con láser para la modificación de cicatrices son prometedoras, pero aún no proporcionan una solución definitiva. Su eficacia solo se ve cuando se usan como parte de un programa de manejo de cicatrices multimodal ${ }^{3}$.

Numerosos estudios han demostrado que los macrófagos pueden orquestar el microambiente desde la etapa inicial de cicatrización de heridas hasta las etapas posteriores de formación de cicatrices. Primero, un mayor número de células $\mathrm{M} 2$ observadas antes de las lesiones se asocian significativamente con la susceptibilidad a la patogénesis de cicatrices anormales. Segundo, la disminución de la expresión de M1 en la etapa temprana y la expresión tardía de M2 en la etapa tardía resultan en la formación de cicatrices patológicas. Tercero, las células M2 se expresan altamente tanto en el margen como en la región superficial, lo que es consistente con la propiedad invasiva de los queloides ${ }^{4}$.

Los estudios histológicos de injertos de grasa han documentado cambios en la textura y apariencia con signos de regeneración que se caracterizan por la neovascularización, aumento del contenido de colágeno e hiperplasia cutánea ${ }^{5-7}$. Esto se traduce en una mejor flexibilidad, color y textura con una mejoría en futuras contracciones.

Sin embargo, el espacio subcutáneo en una lesión por quemadura constituye un ambiente hostil para un injerto de grasa y a menudo compromete el resultado clínico. Por lo tanto, una estrategia óptima sería introducir en el espacio subcutáneo los elementos capaces de inducir la formación de nuevos vasos sanguíneos mientras se asegura la restauración del volumen y regeneración de tejidos.

Las células madre mesenquimáticas (CMM) constituyen una población de células presentes en todos los tejidos, incluyendo la grasa, organizada en el espacio perivascular-11. Como parte de sus actividades trófi$\mathrm{cas}^{12}$, que producen factores angiogénicos tales como el factor de crecimiento endotelial vascular (VEGF) y el factor de crecimiento de hepatocitos, postulados en la supervivencia de los injertos ${ }^{13,14}$. Hoy en día existe una variada tecnología que permite el procesamiento de la grasa con el fin de obtener la fracción del estroma vascular (FEV), que constituye el componente celular, donde se incluyen las CMM y otros tipos de células. Estas técnicas tienen, como un factor común, una digestión enzimática de tejido adiposo usando una u otra forma de la colagenasa, seguida por centrifugación.

La FEV obtenida de esta manera constituye un elemento vascular autólogo de grasa del propio paciente y, como consecuencia, podrían ser readministradas de nuevo al paciente siguiendo una lógica similar a una autotransfusión de sangre u otros hemoderivados (p. ej., plasma rico en plaquetas) ${ }^{15}$. 
El objetivo del artículo es describir la evolución clínica de cuatro pacientes tratados con la FEV derivada del tejido adiposo obtenidos por medio de lipoaspirados humanos y una revisión de la bibliografía.

\section{Materiales y métodos}

Estudio descriptivo, tipo reporte de casos. La población consistió en cuatro pacientes de sexo femenino con cicatrices por quemaduras que consultaron previamente en el Centro Nacional de Quemaduras y Cirugía Reconstructiva (CENQUER) en mayo de 2017. Las muestras de tejido adiposo humano fueron procedentes de liposucciones con zonas donantes en abdomen, flancos y cara interna de los muslos, principalmente. La recogida del tejido adiposo se realizó mediante aspiración utilizando el dispositivo de jeringas de succión y cánulas de punta roma tipo mercedes de 4 y 3 $\mathrm{mm}$ de diámetro, previa infiltración de la zona donante mediante solución salina fisiológica y adrenalina.

Para el aislamiento de la FEV utilizamos un dispositivo médico cerrado (GID SVF-1) que permite la recogida directa del lipoaspirado desde la cánula de liposucción, así como el procesamiento de este de forma rápida y sencilla (The GID Group Inc, Colorado, EE.UU.). El procedimiento empleado fue el siguiente:

- Tres lavados consecutivos del tejido adiposo utilizando solución Ringer lactato suplementada con antibióticos y heparina.

- Digestión enzimática durante 40 minutos a $37{ }^{\circ} \mathrm{C}$ en agitación utilizando el reactivo GID zyme-2.

- Inactivación de la enzima mediante albúmina humana al $2.5 \%$ y centrifugación a 800 G durante10 minutos para obtener el pellet celular (tejido comprimido) que contiene la FEV.

- Este pellet se resuspendió en $20 \mathrm{ml}$ de Ringer lactato mediante una aguja espinal de $14 \mathrm{G}$ (Abbocath) y la suspensión celular obtenida se analizó e inyectó en las cicatrices por quemaduras.

En la primera consulta se procedió a la evaluación general del paciente, registro de historia clínica y obtención del consentimiento informado. Fueron tomadas fotografías de las lesiones con cámara digital en el preoperatorio y a los seis meses.

Para la obtención de los datos preoperatorios y postoperatorios utilizamos la Escala de Vancouver para cicatrices (VSS, Vancouver Scar Assesment) ${ }^{16}$, que categoriza las diferentes características valorables en una cicatriz tales como pigmentación, vascularización, flexibilidad y altura/grosor. Estos parámetros se expresaron sobre un total de 13 puntos. La evaluación de la pigmentación y la vascularización se realizó por observación, la flexibilidad mediante digitopresión del área examinada y la altura/grosor con una regla milimétrica, en la primera visita del paciente y tras seis meses desde el tratamiento.

Para la percepción del paciente con respecto a sus cicatrices utilizamos la Escala del Observador y Paciente para Evaluación de Cicatrices (POSAS, Patient and Observer Scar Assesment Scale), que permite evaluar sobre una medida numérica y de manera subjetiva los síntomas relativos a dolor, escozor, color, rigidez, espesor y alivio ${ }^{17}$. Dicha escala se obtuvo tras el interrogatorio al paciente con una puntuación mínima de 1 (mejor posible) al 10 (peor posible), completándose simultáneamente la ficha escrita de cada paciente para cada parámetro.

Se tomaron muestras de tejido cicatricial antes de iniciar el tratamiento y tras seis meses desde la inyección y fueron evaluados mediante microscopia óptica.

Los procedimientos se realizaron bajo previo consentimiento informado del paciente, la investigación se produjo previo análisis por el Comité de Ética de la Universidad Nacional de Asunción y del Ministerio de Salud como autoridad sanitaria, cumpliendo con las disposiciones de carácter obligatorio que establece el marco jurídico sanitario del país y adaptándose a los principios científicos y éticos que justifican a la investigación médica que se encuentra en los instrumentos internacionales universalmente aceptados.

\section{Resultados}

La población fue de cuatro pacientes, todas de sexo femenino, la edad media \pm desviación estándar fue de $30.5 \pm 7.2$ años, con un rango de 22 a 37 años. El índice de masa corporal (IMC) medio fue de $20 \pm 2$. El promedio de antigüedad de las cicatrices fue de 22 años (Tabla 1). Ninguna paciente presentaba infección, enfermedad o alteración endocrina concomitante. En dos pacientes la ubicación anatómica de las cicatrices correspondió al rostro, una en la pierna y una en el brazo (Tabla 2).

Todas mostraron mejoría en lo que respecta a las características de las cicatrices según la escala VSS del $36 \%$ y según POSAS del 20\% (Tablas 3 y 4).

Se observó aumento de angiogénesis en las muestras analizadas por microscopia óptica a los seis meses en comparación con las muestras del preoperatorio (Figs. 1-4).

Ningún paciente presentó complicaciones con respecto al procedimiento de lipoaspiración. 


\section{Revisión de la literatura}

El lipofilling es beneficioso para el tratamiento de la piel y las cicatrices. En los últimos años, un número limitado de estudios retrospectivos y prospectivos respaldaron observaciones clínicas anecdóticas previas.

La eficacia clínica del lipofilling en áreas de cicatrices está determinada por la mejora de la apariencia de una cicatriz, como el tamaño, el grosor, la rigidez y la decoloración de la cicatriz. En el caso de cicatrices dolorosas, este efecto también se puede medir mediante una disminución del dolor. En la primera parte de este resumen de estudios clínicos, la atención se centra en la capacidad de los lipoinjertos para mejorar varias de las apariencias de cicatrices mencionadas anteriormente, mientras que en la segunda parte se centra en la capacidad de reducir el dolor.

\section{Apariencia de la cicatriz}

Macroscópicamente, las cicatrices se caracterizan por una apariencia diferente a la piel circundante: decoloración, rigidez y aspereza son características de las cicatrices. En los estudios clínicos, se utilizan diferentes medidas de resultado para cuantificar el grado de cicatrización a nivel macroscópico. Los primeros métodos que se utilizan a menudo para evaluar la gravedad de las cicatrices son las escalas de calificación realizadas por el paciente o el observador, en las que se evalúan varios aspectos de la cicatrización (color, rigidez, grosor, irregularidad). Un segundo método consiste en utilizar dispositivos de medición de la elasticidad de la piel o de la pigmentación dérmica.

La eficacia del lipofilling para mejorar la apariencia de las cicatrices se ha investigado en 16 informes de casos o ensayos clínicos ${ }^{18-30}$. En 10 estudios de estas publicaciones, que incluyeron un total de 156 pacientes, se registraron complicaciones: en nueve de estos 10 estudios no se registraron complicaciones, mientras que en un estudio con 12 pacientes se notificó un caso de celulitis como complicación. Por lo tanto, parece que los riesgos de lipofilling en áreas de cicatrices son bastante bajos. Los 14 informes de casos o ensayos clínicos informaron algún grado de mejora en la apariencia de la cicatriz después del lipofilling: en otras palabras, las cicatrices se volvieron menos diferentes de la piel normal y/o se hicieron menos visibles. Sin embargo, el resultado general de estos estudios clínicos no es inequívoco. En primer lugar, no todos los estudios utilizan las mismas medidas de resultado para informar la apariencia de la cicatriz: la mayoría
Tabla 1. Características de los casos en estudio

\begin{tabular}{|l|l|l|}
\hline Edad & Promedio: 30.5 años & Rango de 22 a 37 años \\
\hline Sexo & $\begin{array}{l}\text { Femenino: } 100 \% \\
(\mathrm{n}=4)\end{array}$ & \\
\hline IMC & Promedio: 20 & \\
\hline $\begin{array}{l}\text { Antigüedad } \\
\text { de la cicatriz }\end{array}$ & Promedio: 22 años & Rango de 10 a 30 años \\
\hline
\end{tabular}

IMC: índice de masa corporal.

Tabla 2. Distribución anatómica de las cicatrices

\begin{tabular}{|l|c|c|}
\hline Ubicación anatómica & Frecuencia & Porcentaje \\
\hline Rostro & 2 & $50 \%$ \\
\hline Pierna & 1 & $25 \%$ \\
\hline Brazo & 1 & $25 \%$ \\
\hline Total & 5 & $100 \%$ \\
\hline
\end{tabular}

Tabla 3. Característica de las cicatrices pretratamiento y postratamiento según la escala de Posas

\begin{tabular}{|l|c|c|}
\hline \multirow{2}{*}{} & \multicolumn{2}{|c|}{ Escala Posas } \\
\cline { 2 - 3 } & Pretratamiento & Postratamiento \\
\hline Paciente 1 & 43 & 38 \\
\hline Paciente 2 & 49 & 40 \\
\hline Paciente 3 & 36 & 28 \\
\hline Paciente 4 & 40 & 30 \\
\hline Total & 168 & 136 \\
\hline
\end{tabular}

Tabla 4. Característica de las cicatrices pretratamiento y postratamiento según la escala de Vancouver

\begin{tabular}{|l|c|c|}
\hline \multirow{2}{*}{} & \multicolumn{2}{|c|}{ Escala Vancouver } \\
\cline { 2 - 3 } & Pretratamiento & Postratamiento \\
\hline Paciente 1 & 7 & 4 \\
\hline Paciente 2 & 5 & 3 \\
\hline Paciente 3 & 4 & 3 \\
\hline Paciente 4 & 6 & 4 \\
\hline Total & 22 & 14 \\
\hline
\end{tabular}

de los estudios utilizaron la satisfacción del paciente o escalas de calificación realizadas por el paciente y el observador para la gravedad de la cicatriz para informar el efecto del lipofilling, mientras que otros 

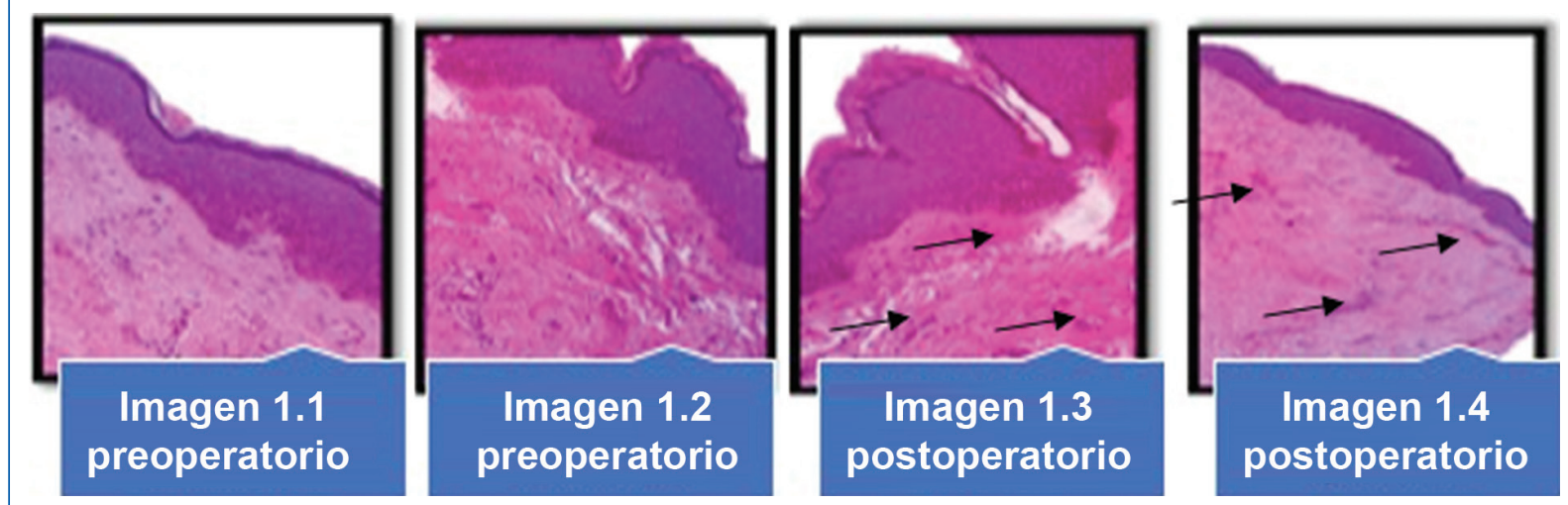

Figura 1. Paciente 1: cicatriz en brazo pretratamiento y postratamiento a los 6 meses (microscopia óptica 200x, tinción con hematoxilina y eosina, las fechas indican la neovascularización).

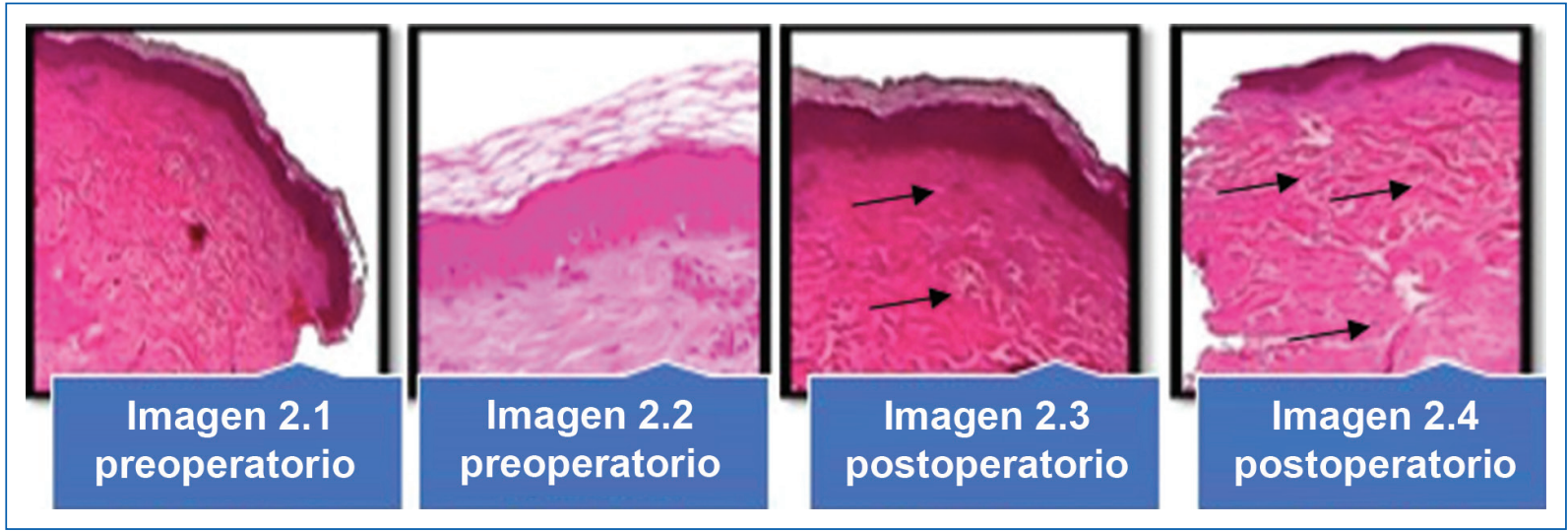

Figura 2. Paciente 2: cicatriz en rostro pretratamiento y postratamiento a los 6 meses (microscopia óptica 200x, tinción con hematoxilina y eosina, las fechas indican la neovascularización).
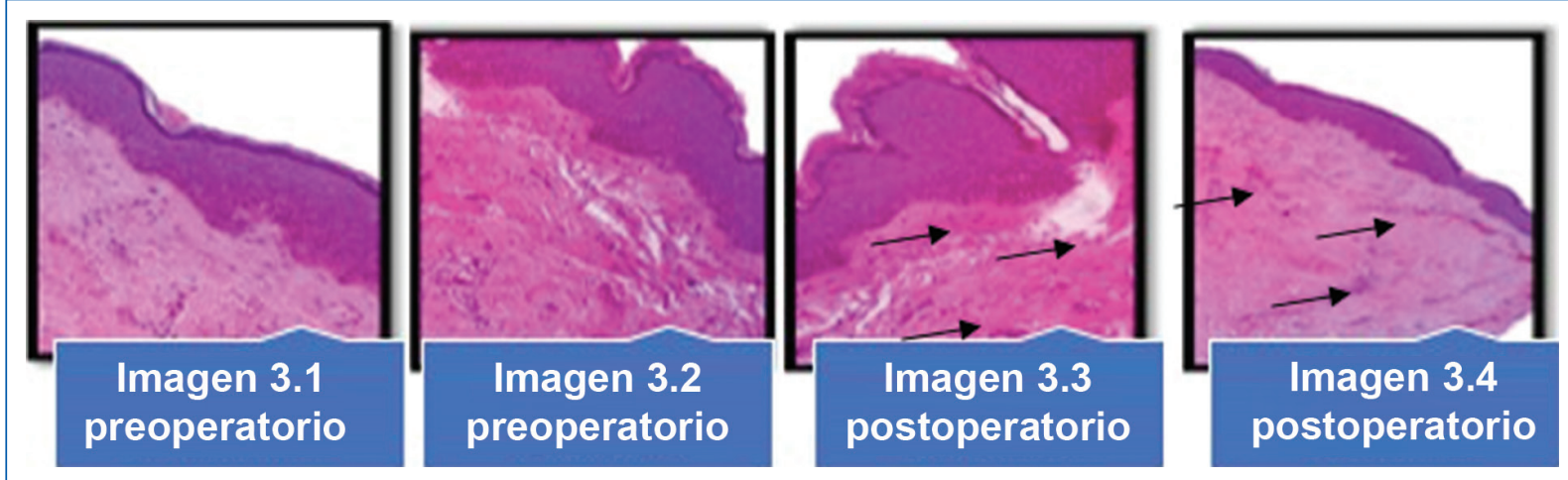

Figura 3. Paciente 3: cicatriz en pierna pretratamiento y postratamiento a los 6 meses (microscopia óptica 200x, tinción con hematoxilina y eosina, las fechas indican la neovascularización).

estudios utilizaron dispositivos de medición para la elasticidad de la piel o dérmica pigmentación. En segundo lugar, si hay o no una mejora en la apariencia de las cicatrices varía dentro de estos estudios: algunos estudios informan una mejoría en la mayoría de los pacientes, en contraste con la ausencia de efecto 


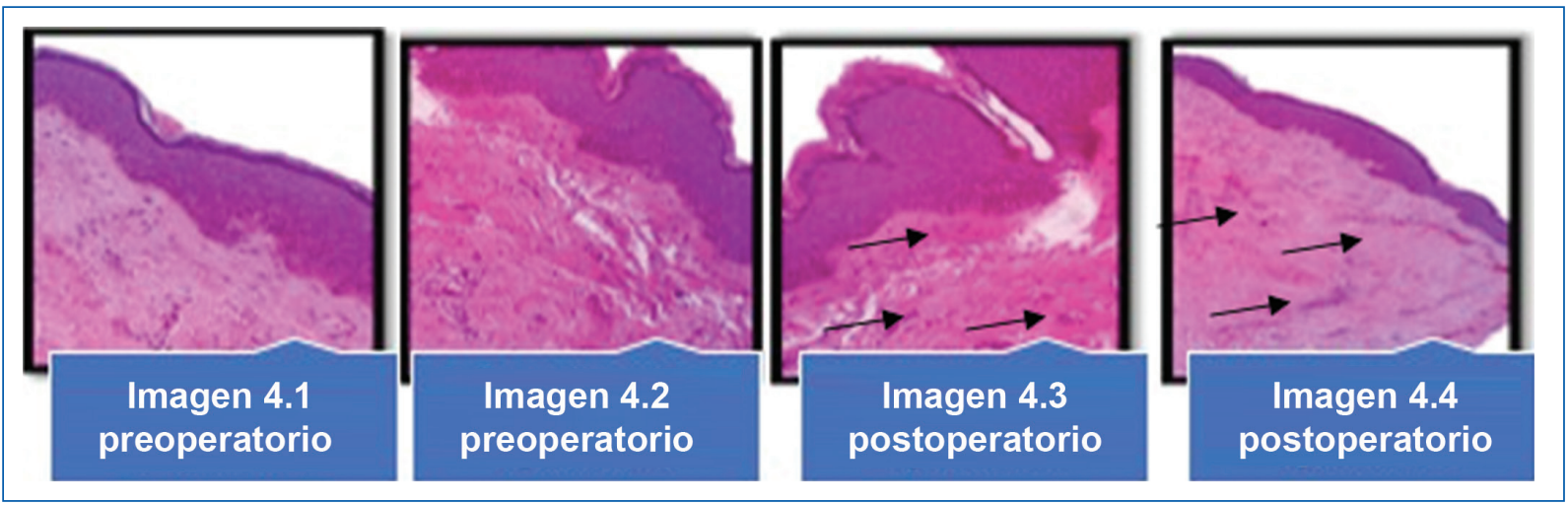

Figura 4. Paciente 4: cicatriz en rostro pretratamiento y postratamiento a los 6 meses (microscopia óptica 200x, tinción con hematoxilina y eosina, las fechas indican la neovascularización).

en otros pacientes. Por último, también, dentro del mismo estudio, se informa una mejora después del lipofilling en una medida de resultado (p. ej., menos rigidez de la cicatriz), pero no hay mejoría en otras medidas de resultado (p. ej., no hay mejoría en la decoloración). Por lo tanto, la tendencia general es que el lipofilling mejora la apariencia de la cicatriz en varias medidas de resultado diferentes, lo que se confirma en dos revisiones sistemáticas ${ }^{31,32}$. Sin embargo, debido a la falta de uniformidad en la intervención y el seguimiento, no se pueden establecer conclusiones definitivas.

Solo cinco estudios controlados bien diseñados tenían objetivos y parámetros de resultado bien definidos, y habían incluido tanto no tratados como trata$\operatorname{dos}^{18,20,24,28,30}$. Cuatro de estos estudios se centraron en los resultados clínicos ${ }^{18,24,28,30}$ y uno aborda los cambios histológicos ${ }^{20}$.

En dos estudios, realizados bajo la supervisión del mismo investigador principal ${ }^{18,30}$, se evalúa el efecto del lipofilling como procedimiento adyuvante para reducir la formación de nuevas cicatrices después de la cirugía. Durante la cirugía primaria de reparación del labio leporino, la eficacia del lipofilling se examina mediante la comparación de imágenes preoperatorias y postoperatorias de los estigmas residuales de la hendidura por un panel de revisores cegado. En comparación con la reparación primaria del labio leporino sin lipofilling, resultó en menos estigmas residuales de la hendidura y, por lo tanto, en una mejor apariencia de la cicatriz. Aparentemente, el lipofilling condujo a la reducción de la formación de cicatrices. Además, las cicatrices ya existentes se pueden tratar mediante el lipofilling: en la reconstrucción mamaria protésica en el contexto de la radioterapia posterior a la mastectomía, el lipofilling posterior a la radioterapia puede reducir el grado de contractura capsular según lo medido por la clasificación de Baker ${ }^{28}$. Aquí, el lipofilling aparentemente puede prevenir o incluso revertir (parcialmente) el proceso fibrótico de la contractura capsular. Otro ejemplo es el tratamiento de cicatrices posquirúrgicas en pacientes con acondroplasia que requieren alargamiento quirúrgico de la extremidad ${ }^{24}$. En este estudio, el lipofilling se comparó con la inyección de solución salina: el lipofilling aumentó significativamente la flexibilidad de la piel y todos menos uno de los parámetros de la escala de evaluación de cicatrices del paciente y del observador mejoraron. Así, el lipofilling mejora aparentemente el aspecto de las cicatrices existentes.

\section{Reducción del dolor}

La eficacia del lipofilling como medio para la reducción del dolor se investigó en cuatro informes de casos o estudios ${ }^{33-36}$. No se registraron complicaciones en seis de siete estudios con un total de 204 pacientes; un estudio no mencionó ninguna complicación. Todos los estudios informaron una reducción significativa del dolor después del tratamiento de las cicatrices dolorosas: solo en dos de estos estudios no se encontraron diferencias en $u^{3}{ }^{34}$ y en dos ${ }^{35}$ pacientes de la población entera. Tres estudios incluyeron grupos de control, donde el lipofilling se comparó con ningún tratamiento ${ }^{33-35}$. Dos de estos estudios, realizados en el mismo instituto, se centraron en el lipofilling como tratamiento para el dolor neuropático después de la mastectomía total ${ }^{34}$ o la cirugía de conservación de la mama ${ }^{36}$. En ambos estudios se demostró que el lipofilling puede reducir el dolor medido en una escala analógica visual en aproximadamente tres puntos en el grupo de lipofilling, en comparación con 
aproximadamente un punto en el grupo de control. El tercer estudio comparó los resultados con una cohorte de pacientes representativa: mujeres que se sometieron a reconstrucción mamaria e irradiación después de una mastectomía ${ }^{35}$. En el grupo de lipofilling hubo una mejora significativa de todos los parámetros de la clasificación LENT-SOMA (dolor, telangiectasias, edema mamario, atrofia y fibrosis) después del tratamiento. Por razones desconocidas, los autores no compararon ni analizaron el grupo de tratamiento con un grupo de control, pero aun así llegaron a la conclusión de que el lipofilling produce alivio del dolor y mejora la apariencia de la cicatriz.

\section{Influencia del lipofilling en cicatrices a nivel tisular}

Microscópicamente, las cicatrices muestran una pérdida de crestas, glándulas sebáceas y folículos pilosos. Además, se caracterizan por un mayor grosor dérmico y epidérmico ${ }^{37,38}$. El engrosamiento epidérmico está causado por una proliferación excesiva de queratinocitos. En la dermis, el engrosamiento es causado por una producción excesiva de matriz extracelular (MEC) por parte de los miofibroblastos, que consisten principalmente en colágeno tipo $I^{39}$. No solo hay un aumento en la cantidad de colágenos, sino también en el grosor de la fibra de colágeno, la maduración y el grado de desorganización ${ }^{38-40}$. Aunque hay un aumento en la cantidad de MEC en las cicatrices, algunos componentes de la piel normal (p. ej., elastina, decorina) son menos abundantes en las cicatrices ${ }^{40}$.

En dos estudios de pacientes se obtuvieron biopsias de piel antes y después del tratamiento de cicatrices con lipofilling ${ }^{20,23}$, un estudio evaluó una serie completa de biopsias de un solo paciente ${ }^{20}$. Tras el lipofilling, la estructura general de la piel mejoró, se remodeló el colágeno y hubo un aumento de la vascularización.

En un estudio grande controlado con placebo se comparó el lipofilling en grandes cicatrices de quemaduras con la inyección de solución salina ${ }^{30}$. En 96 pacientes, la mitad de la cicatriz se inyectó con solución salina (grupo tratado con placebo o simulado), la otra mitad se inyectó con lipoaspirado. Se tomaron y analizaron biopsias de piel a los tres y seis meses. En general, la estructura histológica de las cicatrices volvió a acercarse a la de la piel normal: mejor organización y alineación de las fibrillas de colágeno, mejor vascularización de las papilas dérmicas, menor actividad melanocítica en la epidermis y aumento de la cantidad de fibras de elastina. A nivel celular, hubo un aumento en las divisiones celulares en la capa basal de la epidermis y las células de Langerhans migraron hacia abajo a esta capa basal. Además, disminuyeron los niveles del factor de crecimiento transformante del factor profibrótico beta 1 (TGF- $\beta 1$ ) y los factores proangiogénicos del VEGF.

En resumen, en ambos estudios se observó una mejora histológica en la apariencia de la cicatriz, expresada como una plétora de cambios tanto a nivel histológico como celular. Sin embargo, queda por dilucidar por qué y cómo el lipofilling da como resultado la mejora de todos estos aspectos de la cicatrización antes mencionados, incluida la reducción del dolor.

\section{Estudios en animales}

A diferencia de los estudios clínicos realizados hasta ahora, los modelos animales experimentales han podido demostrar los mecanismos y la influencia del lipofilling en las cicatrices dérmicas, el exterior de la cicatriz y el dolor de la cicatriz.

La histología de las cicatrices se ha investigado en dos estudios que utilizan modelos de daño cutáneo por irradiación en roedores ${ }^{30,33}$. La fibrosis cutánea después de la radiación en general es un problema clínicamente relevante, que puede reproducirse fácilmente en roedores. Después de la radiación, se desarrolla dermatitis, que eventualmente da lugar a una piel fibrótica caracterizada por un engrosamiento epidérmico y un depósito irregular de colágeno en la dermis. Además, en comparación con la piel normal, las áreas de piel irradiadas tienen una mayor densidad de vasos. En dos estudios en ratones se ha demostrado que el tratamiento con lipofilling puede reducir todas estas características distintivas de la piel dañada por radiación ${ }^{30,33}$. Una disminución en los niveles de proteína SMAD3, una proteína clave en la vía profibrótica TGF- $\beta$ / vía de transducción de señales Smad, explica en parte el mecanismo de mejora de la cicatriz ${ }^{33}$. En un modelo ligeramente diferente en ratones con heridas por quemaduras de espesor total, se ha demostrado que el lipofilling conduce a una mejor apariencia de la cicatriz al aumentar los factores proangiogénicos VEGF y el factor 1 derivado de células estromales (y disminuir el factor profibrótico TGF- $\beta 1^{33}$.

Se informó la reducción del dolor neuropático en dos estudios de Huang, et al ${ }^{27}$. La alodinia, percepción dolorosa de un estímulo normalmente no doloroso, después de una lesión por quemadura se evaluó en ratas 
mediante pruebas conductuales. Después de la lesión por quemadura, el lipofilling redujo la alodinia inducida por quemaduras. Por un lado, el lipofilling reduce la fibrosis cutánea y las cicatrices después de una quemadura ${ }^{27}$ y reduce la expresión de mediadores proinflamatorios en la piel ${ }^{27}$. Por otro lado, el lipofilling induce cambios en la médula espinal y también disminuye la activación microglial y disminuye la activación de la vía de transducción de señales proinflamatoria NFkB en las células de la médula espinal ${ }^{27}$.

Se puede concluir que el lipofilling en modelos de roedores para lesiones cutáneas y fibrosis reduce los cambios fibróticos adversos. Esto parece estar mediado por factores del lipoinjerto que pueden inhibir la activación de las vías de transducción de señales tanto fibróticas como inflamatorias.

\section{Conclusión}

La población tratada se beneficia de manera notable en la evolución de las cicatrices, con resultados favorables según la correlación de las dos escalas de evaluación utilizadas tanto en el aspecto estético como en el clínico, en la capacidad funcional, así como en la angiogénesis aparentemente a la microscopia óptica.

La remodelación de las cicatrices utilizando fracción derivada de tejido adiposo del estroma vascular puede plantearse como una alternativa útil en el manejo conjunto 0 aislado de las cicatrices por quemaduras con nula morbilidad para el paciente (nivel de evidencia IV).

Realizado en el Centro Nacional de Quemaduras y Cirugías Reconstructivas y en Hospital de Clínicas de la Universidad Nacional de Asunción.

\section{Financiamiento}

Los dispositivos y enzimas para este estudio fueron donados por el Grupo Humanus-Regenerative Medicine en el marco de la Jornada de Medicina Regenerativa y Cirugía Plástica realizada en la Facultad de Ciencias Médicas en mayo de 2017. Los costos de los estudios y la logística estuvieron a cargo del Centro Nacional de Quemaduras y Cirugías Reconstructivas y los estudios de microscopia a cargo de la Facultad de Ciencias Médicas de la Universidad Nacional de Asunción.

\section{Conflicto de intereses}

Los autores declaran no tener conflictos de intereses.

\section{Responsabilidades éticas}

Protección de personas y animales. Los autores declaran que esta investigación se ha realizado de acuerdo con las recomendaciones internacionales en materia de investigación con seres humanos, cumpliendo con la legislación vigente en nuestro país en materia de investigación y el protocolo fue aprobado por el Comité de Bioética de la Universidad Nacional de Asunción por resolución N. ${ }^{\circ} 17$ en febrero de 2017.

Confidencialidad de los datos. Los autores declaran que han seguido los protocolos de su centro de trabajo sobre la publicación de datos de pacientes.

Derecho a la privacidad y consentimiento informado. Los autores han obtenido el consentimiento informado de los pacientes y/o sujetos referidos en el artículo.

\section{Bibliografía}

1. Finnerty CC, Jeschke MG, Branski LK, Barret JP, Dziewulski P, Herndon DN. Hypertrophic scarring: the greatest unmet challenge after burn injury. Lancet. 2016;388(10052):1427-36.

2. Slemp AE, Kirschner RE. Keloids and scars: a review of keloids and scars, their pathogenesis, risk factors, and management. Curr Opin Pediatr. 2006;18(4):396-402.

3. Tredget EE, Levi B, Donelan MB. Biology and principles of scar manage- ment and burn reconstruction. Surg Clin North Am. 2014;94(4):793-815.

4. Xu X, Gu S, Huang X, Ren J, Gu Y, Wei C, et al. The role of macrophages in the formation of hypertrophic scars and keloids. Burns Trauma. 2020 Mar 11;8:tkaa006.

5. Pretheeban T, Lemos DR, Paylor B, Zhang RH, Rossi FM. Role of stem/ progenitor cells inreparative disorders. Fibrogenesis Tissue Repair. 2012;5(1):20-32.

6. Gimble JM, Katz AJ, Bunnell BA. Adipose derived stem cells for regenerative medicine. Circ Res. 2007:100(9):1249-60.

7. Yang XF, He X, He J, Zhang LH, Su XJ, Dong ZY, et al. High efficient isolation and systematic identification of human adipose-derived mesenchymal stem cells. J Biomed Sci. 2011;18:59-67.

8. Zuk PA, Zhu M, Mizuno H, Huang J, Futrell JW, Katz AJ, et al. Multilineage cells from human adipose tissue: implications for cell-based therapies. Tissue Eng. 2001;7(2):211-28.

9. Rodriguez JP, Murphy MP, Hong S, Madrigal M, March KL, Minev B, et al. Autologous stromal vascular fraction therapy for rheumatoid arthri- tis: rationale and clinical safety. Int Arch Med. 2012;5:5-14

10. Koh YJ, Koh BI, Kim H, Joo HJ, Jin HK, Jeon J, et al. Stromal vascular fraction from adipose tissue forms profound vascular network through the dynamic reassembly of blood endothelial cells. Arterioscler Thromb Vasc Biol. 2011;31(5):1141-50.

11. Astori G, Vignati F, Bardelli S, Tubio M, Gola M, Albertini V, et al.: "In vitro" and multicolor phenotypic characterization of cell subpopulations identified in fresh human adipose tissue stromal vascular fraction and in the derived mesenchymal stem cells. J Transl Med. 2007;5:55-65.

12. Bunnell BA, Estes BT, Guilak F, Gimble JM. Differentiation of adipose stem cells. Methods Mol Biol. 2008:456:155-71.

13. Kachgal S, Putnam AJ. Mesenchymal stem cells from adipose and bone marrow promote angiogenesis via distinct cytokine and protease expression mechanisms. Angiogenesis. 2011;14(1):47-59.

14. Puissant B, Barreau C, Bourin P, Clavel C, Corre J, Bousquet C, et al. Immunomodulatory effect of human adipose tissue-derived adult stem cells: comparison with bone marrow mesenchymal stem cells. $\mathrm{Br} \mathrm{J}$ Haematol. 2005:129(1):118-29.

15. Gonzalez-Rey E, Anderson P, González MA, Rico L, Büscher D, Delgado $M$. Human adult stem cells derived from adipose tissue protect against experimental colitis and sepsis. Gut. 2009;58(7):929-39.

16. Salgado AJ, Reis RL, Sousa NJ, Gimble JM. Adipose tissue derived stem cells secretome: soluble factors and their roles in regenerative medicine. Curr Stem Cell Res Ther. 2010;5(2):103-10. 
17. Casteilla L, Planat-Benard V, Laharrague P, Cousin B. Adipose-derived stromal cells: Their identity and uses in clinical trials, an update. World J Stem Cells. 2011;3(4):25-33.

18. Balkin DM, Samra S, Derek M. Steinbacher. Immediate fat grafting in primary cleft lip repair. J Plast Reconstr Aesthet Surg. 2014;67(12):1644-50.

19. Bollero D, Pozza S, Gangemi EN, de Marchi A, Ganem J, El Khatib AM et al. Contrast-enhanced ultrasonography evaluation after autologous fat grafting in scar revision. G Chir. 2014;35(11-12):266-73.

20. Michaud M, Balardy L, Moulis G, Gaudin C, Peyrot C, Vellas B, et al Proinflammatory cytokines, aging, and age-related diseases. J Am Med Dir Assoc. 2013;14(12):877-82.

21. Coleman SR. Structural fat grafting: More than a permanent filler, plastic and reconstructive surgery. Plast Reconstr Surg. 2006;118(3 Suppl):108S-120S.

22. Guisantes E, Fontdevila J, Rodríguez G. Autologous fat grafting for correction of unaesthetic scars, annals of plastic surgery. Ann Plast Surg. 2012;69(5):550-4

23. Klinger $M$, Marazzi $M$, Vigo $D$, Torre $M$. Fat injection for cases of severe burn outcomes: a new perspective of scar remodeling and reduction. Aesthetic Plast Surg. 2020;44(4):1278-82.

24. Maione L, Vinci V, Caviggioli F, Klinger F, Banzatti B, Catania B, et al. Autologous fat graft in postmastectomy pain syndrome following breast conservative surgery and radiotherapy. Aesthetic Plast Surg. 2014;38(3):528-32.

25. Mazzola IC, Cantarella G, Mazzola RF. Management of tracheostomy scar by autologous fat transplantation: a minimally invasive new approach. J Craniofac Surg. 2013;24(4):1361-4.

26. Kakagia D, Pallua N. Autologous fat grafting: in search of the optimal technique. Surg Innov. 2014;21(3):327-36.

27. Phulpin B, Gangloff $P$, Tran N, Bravetti P, Merlin JL, Dolivet G. Rehabilitation of irradiated head and neck tissues by autologous fat transplantation. Plast Reconstr Surg. 2009;123(4):1187-97.

28. Ribuffo D, Atzeni M, Guerra M, Bucher S, Politi C, Deidda M, et al. Treatment of irradiated expanders: protective lipofilling allows immediate prosthetic breast reconstruction in the setting of postoperative radiotherapy. Aesthetic Plast Surg. 2013;37(6):1146-52.

29. Sardesai MG, Moore CC. Quantitative and qualitative dermal change with microfat grafting of facial scars. Otolaryngol Head Neck Surg. 2007;137(6):868-72.
30. Beer L, Zimmermann M, Mitterbauer A, Ellinger A, Gruber F, Narzt MS, et al. Analysis of the secretome of apoptotic peripheral blood mononuclear cells: impact of released proteins and exosomes for tissue regeneration. Sci Rep. 2015;5:16662.

31. Condé-Green A, Marano AA, Lee ES, Reisler T, Price LA, Milner SM, et al. Fat grafting and adipose-derived regenerative cells in burn wound healing and scarring: a systematic review of the literature. Plast Reconstr Surg. 2016;137(1):302-12.

32. Negenborn VL, Groen JW, Smit JM, Niessen FB, Mullender MG. The use of autologous fat grafting for treatment of scar tissue and scar-related conditions: a systematic review. Plast Reconstr Surg. 2016;137(1):31e-43e.

33. Caviggioli F, Maione L, Forcellini D, Klinger F, Klinger M. Autologous fat graft in postmastectomy pain syndrome. Plast Reconstr Surg. 2011;128(2):349-52.

34. Jha AK, Huang SCC, Sergushichev A, Lampropoulou V, Ivanova Y, Loginicheva $E$, et al. Network integration of parallel metabolic and transcriptional data reveals metabolic modules that regulate macrophage polarization. Immunity. 2015;42(3):419-30.

35. Panettiere P, Marchetti L, Accorsi D. The serial free fat transfer in irradiated prosthetic breast reconstructions. Aesthetic Plast Surg. 2009:33(5):695-700.

36. Rigotti G, Marchi A, Galie M, Baroni G, Benati D, Krampera M, et al. Clinical treatment of radiotherapy tissue damage by lipoaspirate transplant: a healing process mediated by adipose-derived adult stem cells. Plast Reconstr Surg. 2007;119(5):1409-22.

37. Beausang E, Floyd H, Dunn KW, Orton Cl, Ferguson MW. A new quantitative scale for clinical scar assessment. Plast Reconstr Surg. 1998;102(6):1954-61.

38. Ehrlich HP, Desmoulière A, Diegelmann RF, Cohen IK, Compton CC, Garner WL, et al. Morphological and immunochemical differences between keloid and hypertrophic scar. Am J Pathol. 1994:145(1):105-13.

39. Van der Veer WM, Bloemen MC, Ulrich MM, Molema G, van Zuijlen PP, Middelkoop E, et al. Potential cellular and molecular causes of hypertrophic scar formation. Burns. 2009;35(1):15-29.

40. Beausang $\mathrm{E}$, Floyd $\mathrm{H}$, Dunn $\mathrm{KW}$, Orton $\mathrm{Cl}$, Ferguson MW. A new quantitative scale for clinical scar assessment. Plast Reconstr Surg. 1998;102(6):1954-61. 